Martin Thiel • Niklas Ullrich

\title{
Hard rock versus soft bottom: the fauna associated with intertidal mussel beds on hard bottoms along the coast of Chile, and considerations on the functional role of mussel beds
}

Received: 30 November 2000 / Revised: 21 July 2001 / Accepted: 10 December 2001 / Published online: 22 March 2002

(C) Springer-Verlag and AWI 2002

\begin{abstract}
The fauna associated with hard bottom mussel beds along the exposed Pacific coast of Chile was examined. The abundance of adult ( $>10 \mathrm{~mm}$ body length) purple mussels Perumytilus purpuratus varied between 32 and 75 individuals per $50 \mathrm{~cm}^{2}$, and their biomass between 4.8 and $8.6 \mathrm{~g}$ AFDW per $50 \mathrm{~cm}^{2}$ at eight sampling sites between Arica $\left(18^{\circ} \mathrm{S}\right)$ and Chiloé $\left(42^{\circ} \mathrm{S}\right)$. At all sampling sites, the associated fauna was dominated by suspensionfeeding organisms (cirripeds, spionid and sabellid polychaetes, a small bivalve) followed by grazing peracarids and gastropods. Predators and scavengers also reached high abundances while deposit- and detritus-feeding organisms were of minor importance. The majority of organisms associated with these hard bottom mussel beds feed on resources obtained from the water column or growing on the mussels rather than on materials deposited by the mussels. This is in contrast to the fauna associated with mussel beds on soft bottoms, which comprises many species feeding on material accumulated by mussels (faeces and pseudofaeces) and deposited within the mussel bed. Many of the organisms dwelling between mussels both on hard bottoms and on soft bottoms have direct development, but organisms with pelagic development also occur abundantly within mussel beds. We propose that species with direct development are disproportionately favoured by the structurally complex habitat with diverse interstitial spaces between the mussels, which provides ample shelter for small organisms. We conclude that mussels on hard-bottoms primarily provide substratum for associated fauna while mussels on soft bottoms provide both substratum and food resources.
\end{abstract}

Communicated by H. Asmus and R. Asmus

M. Thiel (-

Facultad Ciencias del Mar, Universidad Católica del Norte,

Larrondo 1281, Coquimbo, Chile

e-mail: thiel@nevados.ucn.cl

N. Ullrich

Universität Kiel, Zoologisches Institut,

Arbeitsgruppe Marine Ökologie und Systematik,

Olshausenstrasse 40-60, 24118 Kiel, Germany
Keywords Infauna $\cdot$ Hard bottom $\cdot$ Soft bottom . Exposed shore $\cdot$ Trophic groups

\section{Introduction}

Mussels of the family Mytilidae form beds or patches on substrata ranging from muddy soft bottoms to exposed hard bottoms. These mussel beds provide a favourable habitat for a wide range of associated organisms that find shelter and food between the mussels (Asmus 1987; Commito and Boncavage 1989; Dittmann 1990; Seed and Suchanek 1992). Thus, many associated species are more abundant in mussel beds than in surrounding habitats such as sand or mud bottoms or bare rock surfaces. However, other organisms decrease in abundance or are completely absent in mussel beds (Commito 1987; Dittmann 1990; Tokeshi and Romero 1995). Species richness and diversity of the associated fauna increase with age and size of mussel patches (Tsuchiya and Nishihira 1985, 1986), and decrease with increasing tidal elevation (Seed 1996; Seed and Suchanek 1992; Hertlein 1997). Lintas and Seed (1994) found that most taxa of associated fauna specialise on specific layers within the mussel assemblage from the sediment at the base to the surface of the mussel matrix. In mussel beds covered by algae, barnacles (Balanidae), periwinkles (Littorina littorea) and crabs (especially Carcinus maenas) may be less abundant compared with uncovered mussel beds (Albrecht and Reise 1994; Bertness 1999). The biomass of the associated fauna generally contributes relatively little to the total biomass within mussel beds $(<10 \%$ of the total biomass - Asmus 1987).

Several studies have indicated that distinct groups of organisms are favoured in mussel beds. For example Tokeshi and Romero (1995) have shown that polychaetes are much more abundant in mussel beds than on surrounding mussel-free rock surfaces. In particular, mobile species such as syllid and nereid polychaetes that require shelter on exposed rocky shores may be favoured by structurally complex substrata with many interstitial 
Fig. 1 Size frequency distribution of purple mussels, Perumytilus purpuratus, at the eight sampling sites along the Pacific coast of Chile; at each site six replicate samples (each of $50 \mathrm{~cm}^{2}$ ) were taken, all mussels from each site were pooled

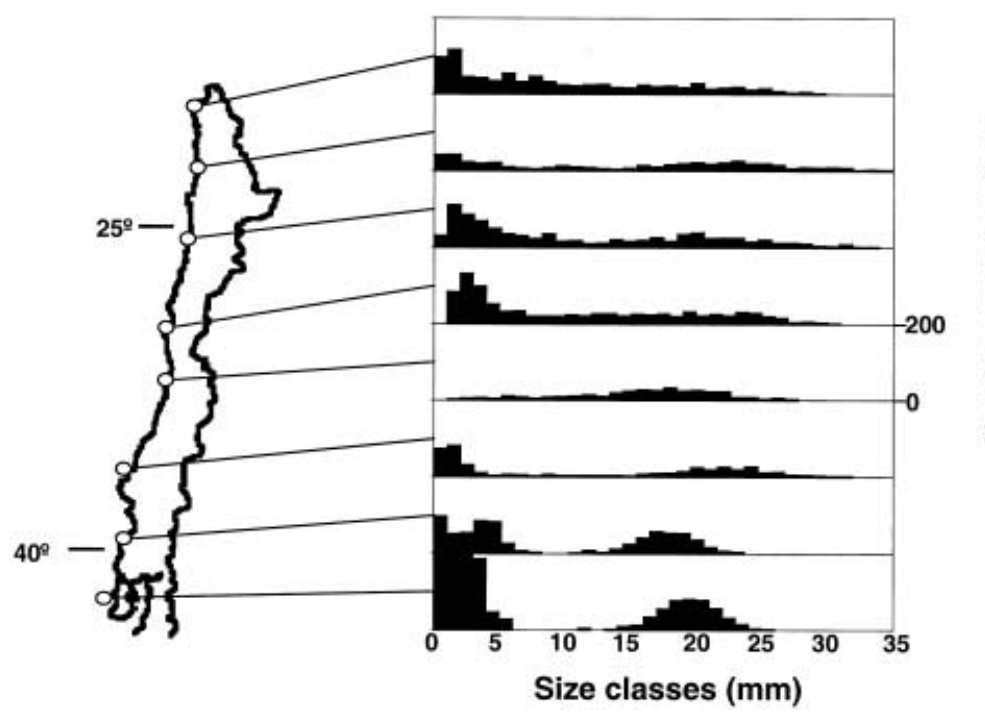

spaces provided by mussels on hard bottoms. Commito and Boncavage (1989), based on their finding of high numbers of oligochaetes in mussel beds, suggested that species with direct development or asexual reproduction may be favoured in dense reefs of suspension-feeders. Dittmann (1990) revealed that deposit-feeding annelids were abundant in mussel beds but suspension-feeding organisms were excluded by the mussels. In general, this short comparison suggests that organisms with distinct trophic and reproductive characteristics are favoured within mussel beds.

Mussels establish dense beds on soft-bottom as well as on hard-bottom habitats. In both environments, mussels provide a highly structured habitat with many interstitial spaces, which differs substantially from the surrounding environments (Seed and Suchanek 1992; Jones et al. 1994). While bare soft bottoms provide a habitat for a rich infauna, the colonisation of bare rock surfaces is restricted to specialists that live on the substratum surface. In soft-bottom environments, the shells of mussels provide the only hard substrate available for some algal and faunal species to attach to (Buschbaum 2001), while mussel beds in hard-bottom environments provide extensive interstitial spaces that can be inhabited by species that otherwise could not gain a hold on wave-exposed rock surfaces (Tokeshi and Romero 1995). Mytilid mussels, through their tendency to form dense assemblages, create a three-dimensional habitat (Alvaredo and Castilla 1996; Guiñez and Castilla 1999) of high spatial complexity (Snover and Commito 1998), thereby rendering it suitable for a wide range of marine invertebrates.

Both on soft bottoms and on hard bottoms, once established, mussel beds persist for long time periods, i.e. many years or decades (e.g. Suchanek 1986; Nehls and Thiel 1993). Individual mussel patches remain in place for sufficiently long time to allow associated fauna to grow and reproduce within the dense interwoven network of byssal threads and mussels. Thus, in both types of environments (hard and soft bottoms) mussel beds increase the diversity of habitat characteristics available to other organisms. The distinct differences between hard-bottom and soft-bottom environments suggest that the functional role of mussel beds in these habitats may differ with respect to the associated fauna.

The main objective of the present study was to describe the fauna associated with hard-bottom mussel beds along the Pacific coast of Chile. The data obtained herein provided the principal information for a comparison of the functional role of mussel beds in hardbottom and soft-bottom environments reported in the literature.

\section{Materials and methods}

The purple mussel (Perumytilus purpuratus Lamarck, 1819) is a common inhabitant of intertidal hard bottoms along the coast of Chile. At wave-exposed sites, mussels may form patches from $<1 \mathrm{~m}^{2}$ to $>100 \mathrm{~m}^{2}$. Often, only one layer of mussels covers the rocks, but with increasing size of the mussels multi-layered patches develop (Alvaredo and Castilla 1996; Guiñez and Castilla 1999), creating cavities that allow even large organisms to find shelter under the cover of the mussels (Navarrete and Castilla 1990).

Samples of $P$. purpuratus and the associated fauna were collected during the austral autumn (April-June 2000) at eight different sites along the Pacific coast of Chile (Fig. 1). At each site, six replicate samples were taken. All mussels from a circle corresponding to the opening of the sampling jar $\left(50 \mathrm{~cm}^{2}\right)$ were carefully scraped from the rock and immediately transferred into the sampling jar together with the entire associated fauna. Results from previous studies on the fauna associated with mussel beds on hard bottoms have indicated that sample sizes between $50 \mathrm{~cm}^{2}$ and $200 \mathrm{~cm}^{2}$ provide relatively good estimates for species and individual numbers (Tsuchiya and Nishihira 1985; Peake and Quinn 1993). Six replicate samples of $50 \mathrm{~cm}^{2}$ surface area thus provide a relatively reliable estimate for the composition of associated fauna. During the sampling process, particular care was taken that all mobile fauna were collected. Samples were preserved in 5\% formalin for storage. In the laboratory, the samples were washed over a $500-\mu \mathrm{m}$ sieve. The entire material retained on the sieve was sorted for small mussels and associated fauna under a dissecting microscope.

Following species identification and counting, biomass was determined for purple mussels and the major taxa of the associated fauna. Specimens were sorted, dry weight was determined follow- 
Fig. 2 Rarefaction curves (individual numbers vs species numbers) for the eight sampling sites along the Pacific coast of Chile; at each site six replicate samples (each of $50 \mathrm{~cm}^{2}$ ) were taken

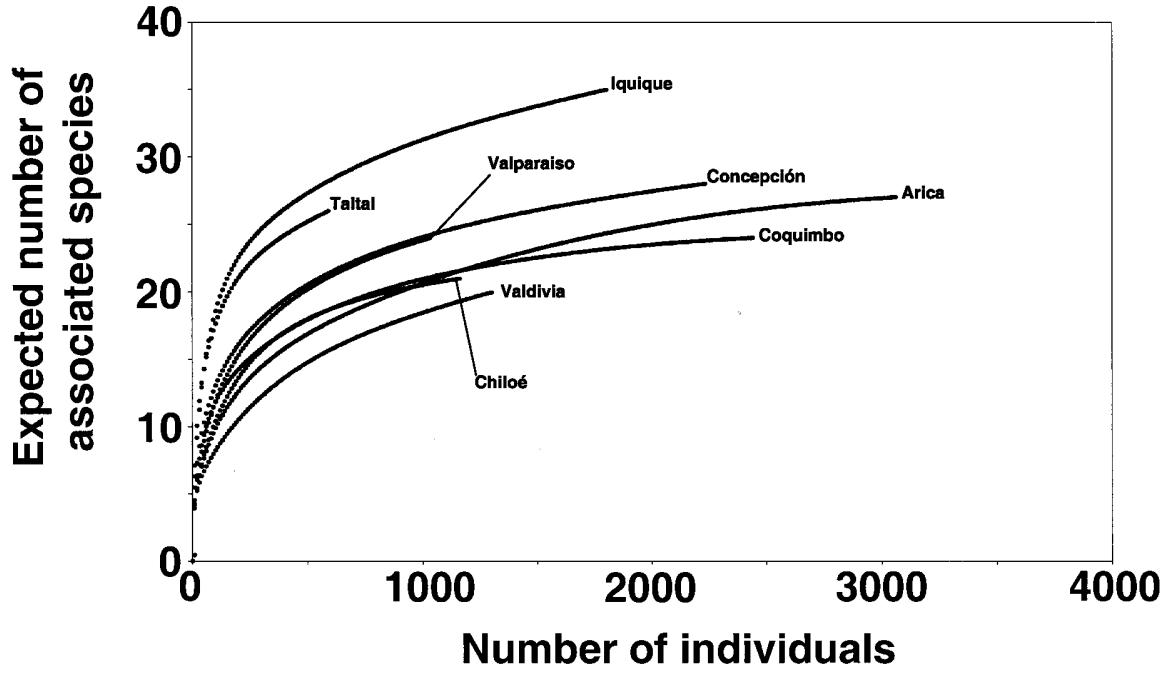

Fig. 3 Average number \pm SE of A species, and $\mathbf{B}$ of individuals of associated fauna in dense beds of purple mussels Perumytilus purpuratus at eight sampling sites along the Pacific coast of Chile; at each site six replicate samples (each of $50 \mathrm{~cm}^{2}$ ) were taken; stars indicate significant differences between immediately neighbouring sites $(P<0.05)$; KruskalWallis followed by non-parametric Tukey (after rank-transformation)

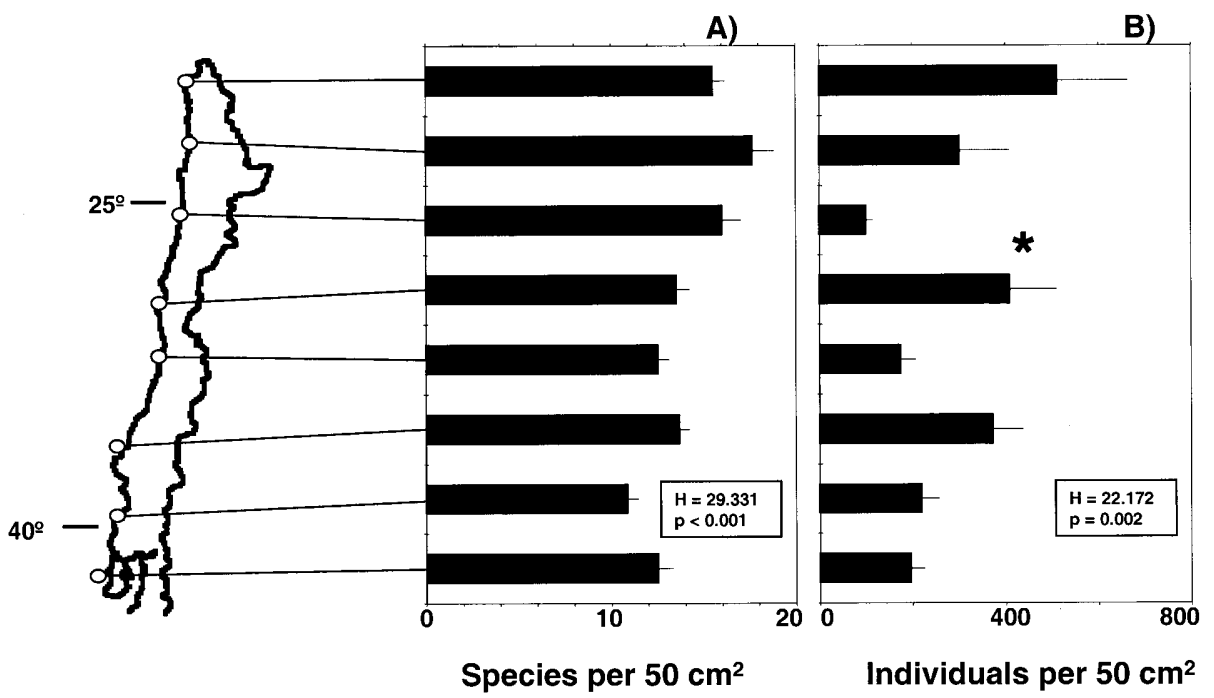

ing drying at $70^{\circ} \mathrm{C}$ for $24 \mathrm{~h}$, and ash weight was measured following combustion at $500^{\circ} \mathrm{C}$ for $6 \mathrm{~h}$. Based on a sample of 492 purple mussels $>10 \mathrm{~mm}$ body length (BL) a length-weight relation was determined and used to calculate the individual biomass of all other purple mussels $>10 \mathrm{~mm}$ BL. For the associated fauna an individual-based average biomass was determined and used to calculate the biomass of the respective species in each sample.

An ANOVA was employed to examine for statistical differences between sampling sites. Since in most cases the variances were not homogeneous, a non-parametric ANOVA (KruskalWallis) was used. The Tukey post-hoc test was employed after rank-transformation of the original data (Zar 1984). Rarefaction curves were produced using the program BioDiversity-Pro freely available from The Scottish Association for Marine Science.

Published data sets on the associated fauna from soft-bottom and hard-bottom mussel beds were examined for information on the abundance of associated fauna. Only studies in which samples had a minimum surface area of $50 \mathrm{~cm}^{2}$ were considered for inclusion in this comparison. The abundance values reported for individual taxa were averaged and transferred to a value of individuals per $100 \mathrm{~cm}^{2}$ in order to allow for direct comparison between different studies. The studies on the fauna associated with hardbottom mussel beds considered in all cases the entire fauna down to the bare rock surface. Samples from soft-bottom mussel beds usually considered the entire fauna down to uninhabited sediment layers.

\section{Results}

The abundance of purple mussels $>10 \mathrm{~mm}$ ranged between 32.2 \pm 6.5 (mean \pm SD) (Concepción) and $74.5 \pm 11.5$ (Chiloé) individuals per $50 \mathrm{~cm}^{2}$, and their biomass ranged between $4.8 \pm 1.1$ (Valparaíso) and $8.6 \pm 0.9$ (Taltal) $\mathrm{g}$ AFDW per $50 \mathrm{~cm}^{2}$ at the eight sampling sites. The mussel size ranged from 0.5 to $34.5 \mathrm{~mm}$ BL. With the exception of one sampling site (Valparaíso) where small mussels were lacking, small $(<5 \mathrm{~mm} \mathrm{BL})$ and intermediate-sized mussels (15-24 mm BL) dominated in the samples (Fig. 1)

At most sampling sites, the rarefaction curves had similar shapes, reaching the asymptote (Fig. 2). This indicates that the fauna associated with $P$. purpuratus had been representatively sampled at most sampling sites - an increase in sampling effort would not have revealed many more additional species. The mean number of associated species varied between 10.8 and 17.7 species per $50 \mathrm{~cm}^{2}$ and the mean number of total individuals between 99 and 511 individuals per $50 \mathrm{~cm}^{2}$ at the eight sampling sites (Fig. 3). 
Table 1 Species associated with purple mussels, Perumytilus purpuratus, along the coast of Chile, and sampling sites at which they were recorded. Sites: 1 Arica, 2 Iquique, 3 Taltal, 4 Coquimbo, 5 Valparaiso, 6 Concepción, 7 Valdivia, 8 Chiloé

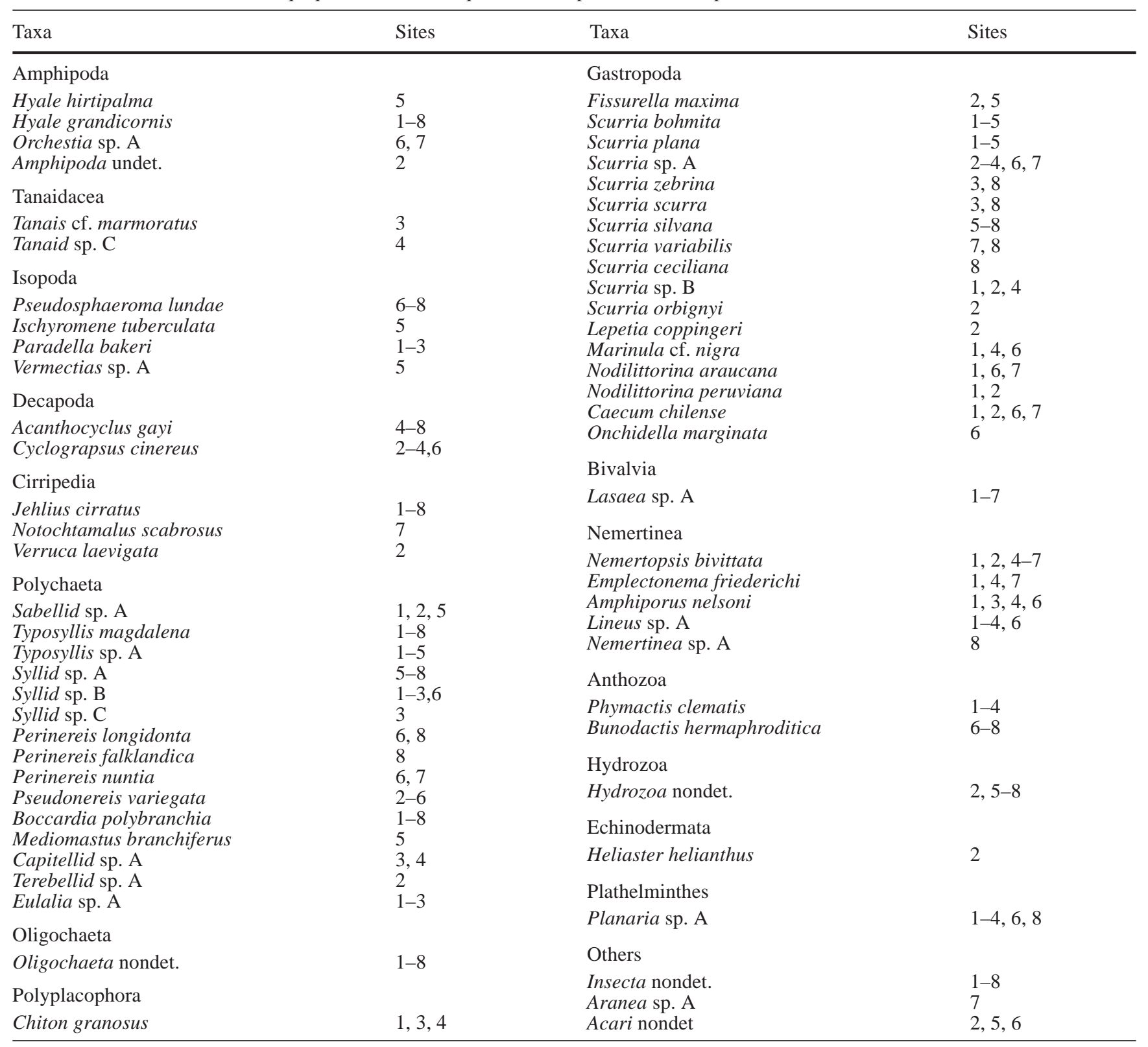

The major taxa were represented at all sampling sites, but some taxa only occurred at some sites (Fig. 4, Table 1). Polychaetes and bivalves (other than $P$. purpuratus) reached the highest abundances of the taxa associated with P. purpuratus (Fig. 4). Nemerteans and turbellarians (macrofauna species) reached high abundances at the four northernmost sites but were absent or only occurred in low numbers at the four southernmost sites. Insect larvae showed a reverse trend, with highest abundances at the four southernmost sites. Some taxa, such as echinoderms and sipunculids, only occurred as single individuals at some sites but were completely absent at most sites (others in Fig. 4).
Suspension-feeding organisms were numerically most abundant in mussel beds formed by $P$. purpuratus (Fig. 5). The non-parametric Kruskal-Wallis test revealed significant differences $(H=18.091 ; P=0.012)$, but no sites differed significantly from the immediately neighbouring sites (Fig. 5). Within the grazers and predators/scavengers significant differences were found between several neighbouring sites indicating a higher variability in these groups (Fig. 5). Suspension-feeding organisms also reached the highest biomass of associated fauna at most sites, followed by predators/scavengers and grazers (Fig. 6). Deposit and detritus feeders (primarily oligochaetes and insect larvae) reached relatively 
Fig. 4 Average numbers of faunal taxa associated with purple mussels $P$. purpuratus at eight sampling sites; at each site six replicate samples (each of $50 \mathrm{~cm}^{2}$ ) were taken

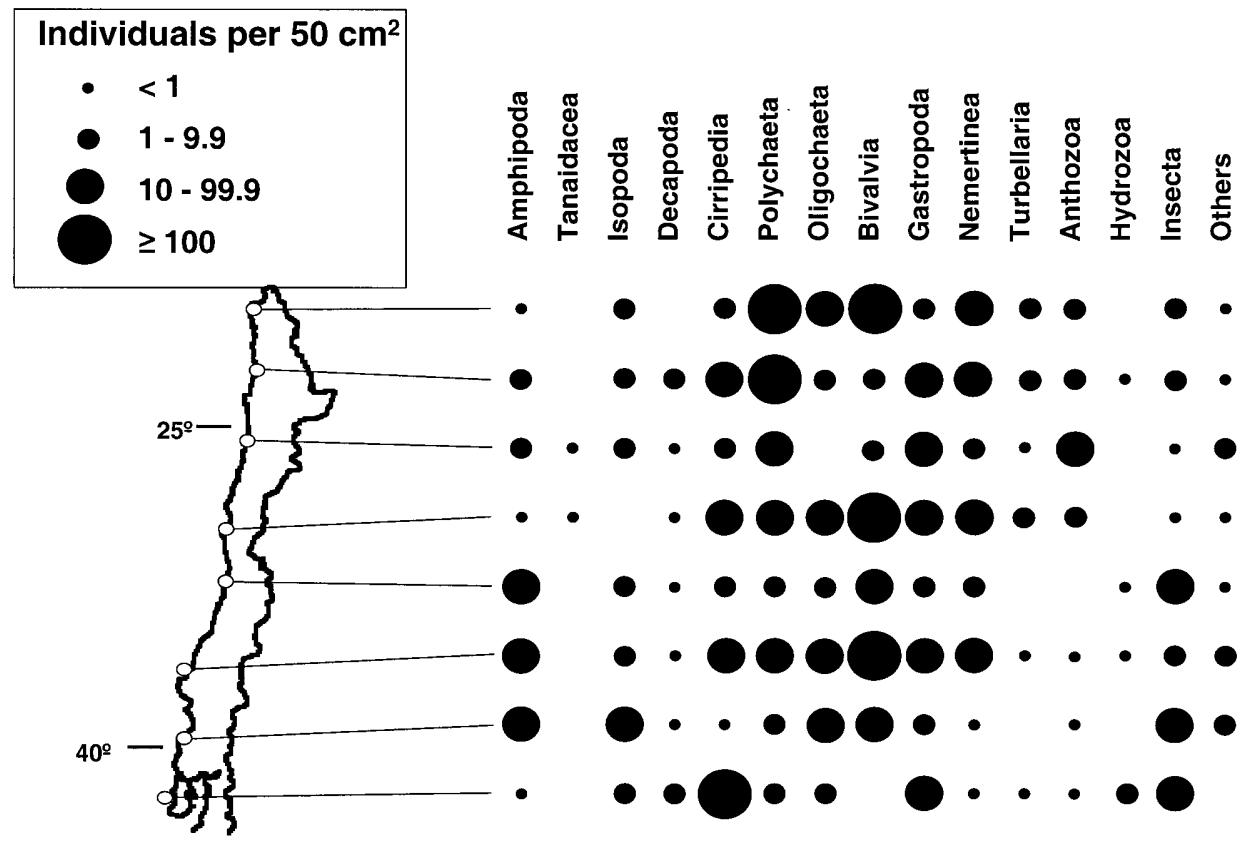

Fig. 5 Average numbers \pm SE of trophic groups of fauna associated with purple mussels $P$. purpuratus at eight sampling sites; at each site six replicate samples (each of $50 \mathrm{~cm}^{2}$ ) were taken; stars indicate significant differences between immediately neighbouring sites $(P<0.05)$; Kruskal-Wallis followed by non-parametric Tukey (after rank-transformation)
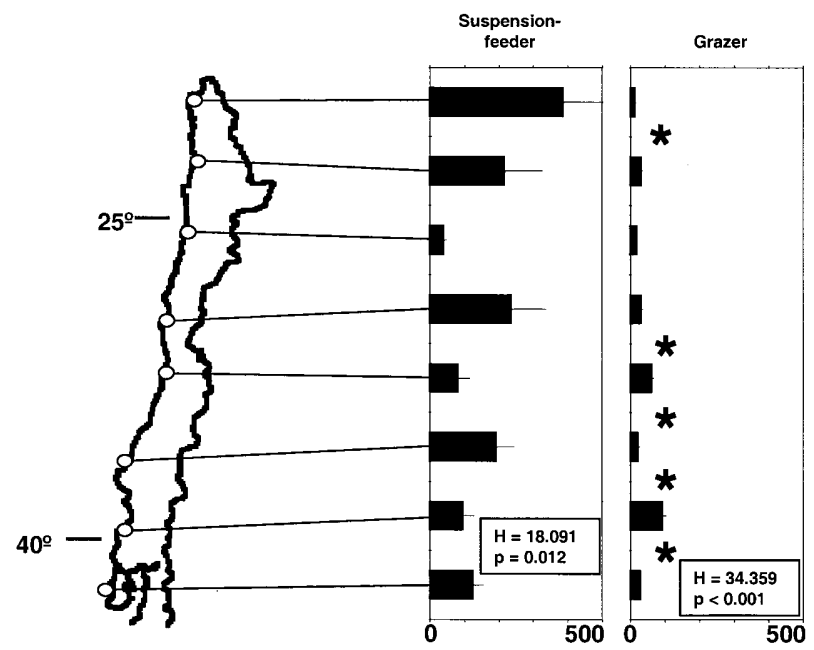

Deposit- $I$ Detritus-feeder Predatorl

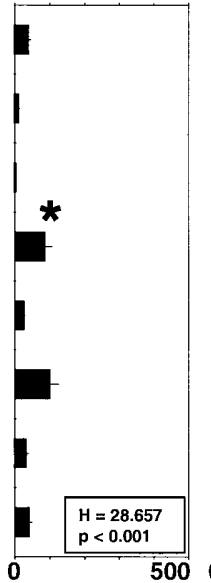
Scavenge

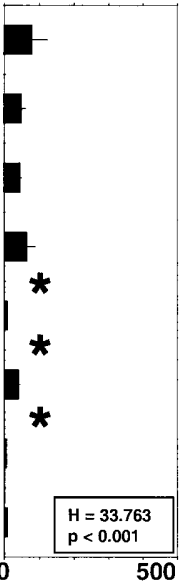

Individuals per $50 \mathrm{~cm}^{2}$

Table 2 Abundance $( \pm \mathrm{SE})$ and reproductive traits of major macrofauna species associated with purple mussels, Perumytilus purpuratus, along the coast of Chile. Larval stage: $p$ pelagic, $b$ benthic, $b / p$ both reported, ? unknown

\begin{tabular}{lllc}
\hline Species & Taxa & Larval stage & Individuals per $50 \mathrm{~cm}^{2}$ \\
\hline Lasaea sp. A & Bivalvia & $\mathrm{b}$ & $84.3 \pm 29.6$ \\
Scurria bohmita & Gastropoda & $\mathrm{p} ?$ & $3.9 \pm 1.6$ \\
Onchidella marginata & Gastropoda & $\mathrm{p} ?$ & $3.0 \pm 3.0$ \\
Pseudosphaeroma lundae & Isopoda & $\mathrm{b}$ & $8.1 \pm 7.7$ \\
Hyale grandicornis & Amphipoda & $\mathrm{b}$ & $5.5 \pm 3.1$ \\
Hyale hirtipalma & Amphipoda & $\mathrm{b}$ & $6.3 \pm 6.3$ \\
Jehlius cirratus & Cirripedia & $\mathrm{p}$ & $26.9 \pm 14.4$ \\
Verruca laevigata & Cirripedia & $\mathrm{p}$ & $4.2 \pm 4.2$ \\
Oligochaeta nondet. & Oligochaeta & $\mathrm{b}$ & $30.3 \pm 13.0$ \\
Boccardia polybranchia & Polychaeta & $\mathrm{b}$ & $48.4 \pm 22.8$ \\
Typosyllis magdalena & Polychaeta & $\mathrm{b}$ & $2.8 \pm 1.2$ \\
Typosyllis sp. A & Polychaeta & $\mathrm{b}$ & $3.4 \pm 2.4$ \\
Sabellid sp. A & Polychaeta & $\mathrm{b}$ & $2.6 \pm 2.4$ \\
Nemertopsis bivittata & Nemertinea & $\mathrm{p} ?$ & $15.2 \pm 6.7$ \\
Lineus sp. A & Nemertinea & $\mathrm{p} ?$ & $4.2 \pm 1.7$ \\
Turbellaria nondet. & Plathelminthes & $\mathrm{b} / \mathrm{p}$ & $3.6 \pm 1.7$ \\
Phymactis clematis & Anthozoa & $\mathrm{p}$ & $3.1 \pm 1.6$ \\
Insecta nondet. & Insecta & $?$ & $9.5 \pm 3.8$ \\
\hline
\end{tabular}


Fig. 6 Average biomass \pm SE of trophic groups of fauna associated with purple mussels $P$. purpuratus at eight sampling sites; at each site six replicate samples (each of $50 \mathrm{~cm}^{2}$ ) were taken; stars indicate significant differences between immediately neighbouring sites $(P<0.05)$; Kruskal-Wallis ollowed by non-parametric Tukey (after rank-transformation)

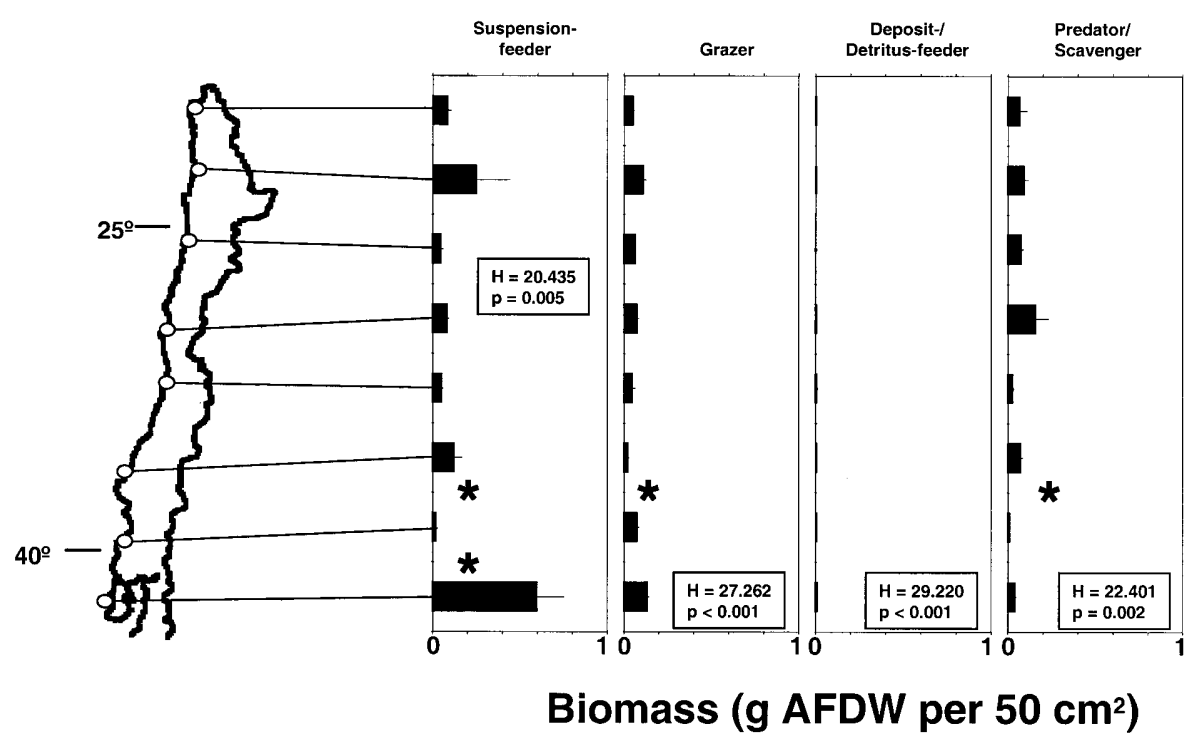

high densities at some sites (Fig. 5), but their biomass was of minor importance (Fig. 6). Thus, also with respect to biomass, most sites are dominated by suspension feeders, followed by grazers and predator/scavengers.

Many of the most abundant species found in mussel beds along the coast of Chile have benthic larval stages (Table 2). Taxa such as amphipods, isopods, syllid polychaetes, oligochaetes and the small bivalve Lasaea sp. release advanced larval stages or small juveniles directly into the adult habitat. Thus, offspring of these taxa may establish within the parental habitat. However, species with pelagic larval stages such as cirripeds, gastropods, nereid polychaetes and probably most of the nemertean species also occurred in high numbers between purple mussels (Table 2).

\section{Discussion}

Mussel beds of $P$. purpuratus harboured an abundant and diverse fauna of associated species. While the abundance and biomass of different taxa associated with mussels was variable among different sites along the Pacific coast of Chile, two consistent patterns emerged: the associated fauna was dominated by suspension-feeding species, and species with direct development were abundant in the mussel beds. These results suggest that mussel beds of $P$. purpuratus serve a specific functional role on hard bottoms. In the following discussion it will be examined whether these findings can be generalised for mussel beds on hard bottoms and how this compares to the functional role of mussel beds on soft bottoms.

Functional role of mussel beds on hard bottoms and soft bottoms

Several previous studies have documented the high abundance of polychaetes, peracarid crustaceans and small bivalves in both hard- and soft-bottom mussel beds (Tsuchiya and Nishihira 1985, 1986; Jacobi 1987; Tsuchiya and Retière 1992; Topaloglu and Kihara 1993; Lintas and Seed 1994; Tokeshi 1995; Tokeshi and Romero 1995). These small organisms find shelter from predators and wave-exposure between the mussels on hard bottoms that otherwise offer little structural support. Associated species comprise highly mobile (nereid and syllid polychaetes, isopod and amphipod peracarids) as well as more sedentary organisms (sabellid and spionid polychaetes, tanaid and some amphipod peracarids). Mobile species roam in the complex matrix of the mussels searching for prey or detritus retained in interstitial spaces. Sedentary species attach self-constructed tubes between the mussels feeding primarily on allochthonous material that is continuously imported into the mussel bed. Nemerteans are also abundant in these biogenic habitats of high structural complexity (Thiel and Kruse 2001) where they probably feed on their preferred prey items, namely polychaetes and amphipods (McDermott and Roe 1985). The high densities of these predators found in the present study indicate strong interspecific interactions among the fauna associated with mussel beds on hard bottoms as had also been shown by Navarrete and Castilla (1990). Few of the organisms found in hard-bottom mussel beds feed on material provided directly by the mussels (faeces and pseudofaeces). Thus, mussels on hard bottoms primarily provide structural protection for the associated fauna, similar to other habitat-forming organisms such as corals, ascidians, sponges and sabellariid polychaetes (see e.g. Nelson and Demetriades 1992).

A comparison between the fauna found in mussel beds on hard bottoms and on soft bottoms reported in the literature shows that crustaceans and polychaetes reach high abundances in mussel beds in both environments (Table 3). Non-mytilid bivalves were much more abundant in mussel beds on hard bottoms than on soft bottoms while the reverse pattern was true for oligochaetes. 


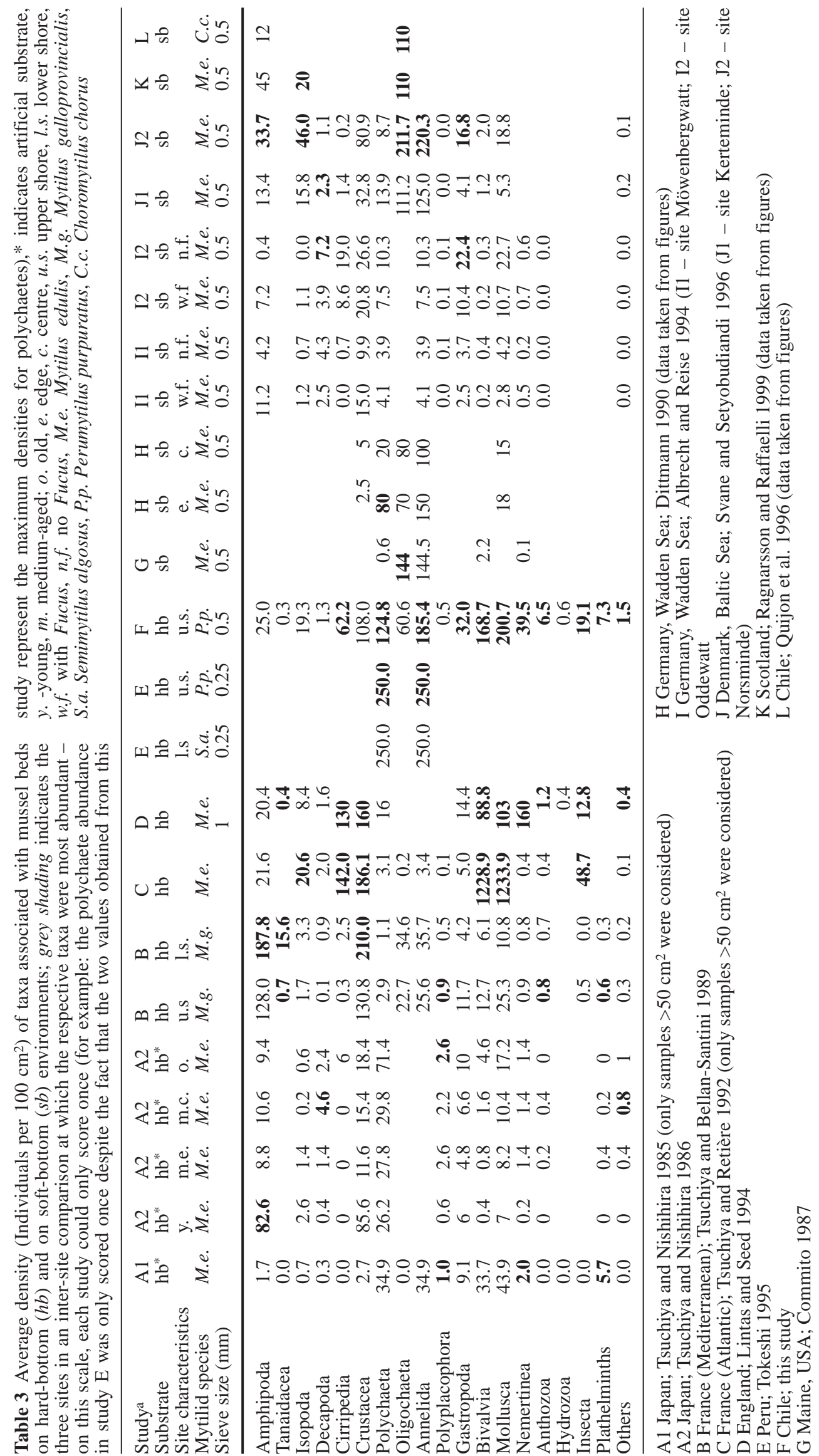


Table 4 Average biomass $\left(\mathrm{g} \mathrm{AFDW} \mathrm{m}{ }^{-2}\right.$ ) of taxa associated with mussel beds on hardbottom $(h b)$ and on soft-bottom $(s b)$ environments. M.e. Mytilus edulis, P.p. Perumytilus purpuratus

\begin{tabular}{|c|c|c|c|c|}
\hline \multirow{4}{*}{$\begin{array}{l}\text { Study } \\
\text { Substrate } \\
\text { Site characteristics } \\
\text { Mytilid species } \\
\text { Sieve size (mm) }\end{array}$} & \multirow{4}{*}{$\begin{array}{l}\text { Asmus } 1987 \\
\text { sb } \\
\text { M.e. } \\
0.5\end{array}$} & \multicolumn{2}{|c|}{ Nehls et al. 1997} & \multirow{2}{*}{$\begin{array}{l}\text { This study } \\
\text { hb }\end{array}$} \\
\hline & & sb & sb & \\
\hline & & M.e. & M.e. & P.p. \\
\hline & & 0.5 & 0.5 & 0.5 \\
\hline Amphipoda & 0.0 & & & 1.1 \\
\hline Tanaidacea & & & & 0.0 \\
\hline Isopoda & 0.0 & & & 0.8 \\
\hline Decapoda & 1.5 & 15.0 & 4.0 & 1.5 \\
\hline Cirripedia & 8.4 & & & 25.9 \\
\hline Polychaeta & 1.8 & 5.0 & 5.0 & 11.2 \\
\hline Oligochaeta & 0.9 & & & 0.1 \\
\hline Bivalvia & 1.5 & & & 1.6 \\
\hline Gastropoda & 20.6 & & & 10.5 \\
\hline Nemertinea & 0.1 & & & 3.7 \\
\hline Anthozoa & 0.0 & & & 0.6 \\
\hline Hydrozoa & & & & 0.0 \\
\hline Chelicerata & & & & 0.1 \\
\hline Planaria & & & & 0.2 \\
\hline Insecta & & & & 0.4 \\
\hline Echinodermata & 0.0 & & & 0.1 \\
\hline Ascidia & 0.0 & & & \\
\hline Others & & 45.0 & 30.0 & \\
\hline Total associated fauna & 34.8 & 65.0 & 39.0 & 57.8 \\
\hline Mytilids <10 mm & & & & 31.3 \\
\hline Mytilids >10 mm & & & & 1380.8 \\
\hline Mytilids total & 1200.0 & 800.0 & 1600.0 & 1412.1 \\
\hline Total biomass & 1234.8 & 865.0 & 1639.0 & 1469.9 \\
\hline Associated fauna (\% of total) & $2.8 \%$ & $7.5 \%$ & $2.4 \%$ & $3.9 \%$ \\
\hline
\end{tabular}

These strong differences in the taxonomic composition of the fauna in mussel beds also indicate differences in the functional role of mussel beds on hard bottoms compared with those on soft bottoms. Mussel beds on hard bottoms often establish on sites that are exposed to strong wave action, and material discarded by the mussels (faeces and pseudofaeces) is immediately washed away by wave action. In contrast, mussel beds on soft bottoms usually establish in sheltered areas, because on exposed tidal flats they cannot withstand strong storms (Nehls and Thiel 1993). Thus, mussel beds on soft bottoms often develop and persist in areas of limited waveaction and consequently a large proportion of the faeces and pseudofaeces from the mussels are deposited directly within the mussel beds (Hild and Günther1999). The mussels themselves can survive in this depositional environment by changing their location in the mussel matrix (Okun 1999), but if sediment deposition is too strong even mussels die under the mud deposits (Albrecht and Reise 1994). Probably this depositional environment in soft-bottom mussel beds does not permit the persistence of non-mytilid bivalves (and other suspension feeders) that abound in hard-bottom mussel beds. However, deposit-feeding annelids, in particular oligochaetes, appear to benefit from the mud deposits that accumulate in softbottom mussel beds as shown by their high densities in this habitat (Commito 1987; Commito and Boncavage 1989; Dittmann 1990; Kröncke 1996; Quijón et al. 1996; Villbrandt et al. 1999). The high organic content of deposited sediments can be exploited by these depositfeeding annelids (Mayer et al. 1997) which may directly invert assimilated energy into new offspring. Svane and Setyobudiandi (1996) suggested a direct relationship between the degree of organic enrichment and the number of deposit-feeding annelids in mussel beds, as was also found by Norkko and Bonsdorff (1996) and Thiel and Watling (1998) under algal mats.

Mussel beds both on hard bottoms and on soft bottoms support a wide diversity of different trophic groups that are favoured by the structural protection within the mussel matrix. In addition to this protective function, mussels living on soft bottoms also provide food resources in the form of faeces and pseudofaeces for associated fauna, which appear to be of little importance in hard-bottom mussel beds.

The habitat-forming mussels themselves reach very high biomass both on soft bottoms and on hard bottoms (Table 4; Reise et al. 1994). The associated fauna usually constitutes only about $2-8 \%$ of the total biomass within mussel beds, and values found in the present study are similar to those reported from soft bottoms (but see Buschbaum 2000). The biomass of associated fauna within mussel beds often does not exceed that of fauna in surrounding habitats (Asmus 1987; Nehls et al. 1997), but the species composition within mussel beds often is substantially different from that outside mussel beds (soft bottoms - see e.g. Dittmann 1990; hard bottoms see e.g. Tokeshi and Romero 1995). Thus, mussel beds do not necessarily enhance biomass (or production) of associated fauna but they provide a habitat for particular species that otherwise could not exist in the respective hard-bottom or soft-bottom environments. 


\section{Reproductive traits of associated fauna}

Previous studies have remarked that organisms that occur in high densities in soft-bottom mussel beds are characterised by direct development or benthic larval stages (Commito 1987; Commito and Boncavage 1989; Dittmann 1990). The present study also revealed high abundances of species with direct development in hardbottom mussel beds. Similarly, many taxa commonly found in hard-bottom mussel beds such as peracarid crustaceans, syllid and sabellid polychaetes, and small bivalves Lasaea spp. (Tsuchiya and Bellan-Santini 1989; Ong Che and Morton 1992; Tsuchiya and Retière 1992; Lintas and Seed 1994; Tokeshi and Romero 1995) release fully developed juveniles or advanced larval stages into the parental environment. The hypothesis has been put forth that these organisms with direct development are resistant to active ingestion by suspensionfeeding mussels or to the sedimentary environment produced by mussel faeces and pseudofaeces (Commito 1987; Dittmann 1990). Species with direct development are not exposed to the negative effects of adult-larval interactions, thereby partly explaining their high densities in mussel beds. However, it should at this point be noted that organisms with pelagic development such as barnacles, some polychaete species and juvenile mussels themselves also establish continuously and often in large numbers in mussel beds [see e.g. high biomass of cirripeds in Asmus (1987) and Buschbaum (2000); large numbers of juvenile mytilids in McGrorty and GossCustard (1991)]. In the present study, large numbers of recently settled cirripeds and mytilids were found at some sites, supporting the notion that these species with pelagic larval stages can successfully settle in dense mussel beds. Thus, exclusion of arriving larvae by the habitat-forming mussels does not appear to be the only factor favouring the relatively high abundance of organisms with direct development. These latter organisms may particularly benefit from the structurally complex and protected microhabitat that mussel beds constitute. The interstitial space between the mussels may provide ideal shelter both for parents and offspring of the species with direct development, most of which are medium-sized macrofauna (1-10 mm BL). Species with direct development may rapidly build large populations in mussel beds, because they release their offspring directly within the mussel beds (and other biogenic habitats) that usually develop in areas with high food supply (see also Crooks and Khim 1999; Thiel and Vásquez 2000). Females that incubate embryos or larvae within or on their bodies may find optimal conditions for successful reproduction in mussel beds. Their offspring, upon being released, may remain in the parental habitat. This "neighbourhood recruitment" may thus primarily be responsible for the high abundance of species with direct development compared to that of species with pelagic larval stages that have to take a long detour via the water column.
Acknowledgements We are most grateful to Prof. N. Rozbaczylo for help with identification of the polychaetes. As always, D. Lancellotti helped in many respects - we are very thankful for his cheerful support. We also thank two anonymous reviewers and C. Buschbaum for comments on the final manuscript. Financial support for this study was received in form of FONDECYT 3980002 .

\section{References}

Albrecht A, Reise K (1994) Effects of Fucus vesiculosus covering intertidal mussel beds in the Wadden Sea. Helgol Meeresunters 48:243-256

Alvaredo JL, Castilla JC (1996) Tridimensional matrices of mussels Perumytilus purpuratus on intertidal platforms with varying wave forces in central Chile. Mar Ecol Prog Ser 133:135-141

Asmus H (1987) Secondary production of an intertidal mussel bed community related to its storage and turnover compartments. Mar Ecol Prog Ser 39:251-266

Bertness MD (1999) The ecology of Atlantic shorelines. Sinauer, Sunderland, Mass.

Buschbaum C (2000) Direct and indirect effects of Littorina littorea (L.) on barnacles growing on mussel beds in the Wadden Sea. Hydrobiologia 440:119-128

Buschbaum C (2001) Siedlungsmuster und Wechselbeziehungen von Seepocken (Cirripedia) auf Muschelbänken (Mytilus edulis L.) im Wattenmeer. PhD thesis, University of Hamburg, Germany

Commito JA (1987) Adult-larval interactions: predictions, mussels and cocoons. Estuar Coast Shelf Sci 25:599-606

Commito JA, Boncavage EM (1989) Suspension-feeders and coexisting infauna: an enhancement counterexample. J Exp Mar Biol Ecol 125:33-42

Crooks JA, Khim HS (1999) Architectural vs. biological effects of a habitat-altering exotic mussel, Musculista senhousia. J Exp Mar Biol Ecol 240:53-75

Dittmann S (1990) Mussel beds - amensalism or amelioration for intertidal fauna? Helgol Meeresunters 44:335-252

Guiñez R, Castilla JC (1999) A tridimensional self-thinning model for multilayered intertidal mussels. Am Nat 154:341357

Hertlein A (1997) Assoziierte Epifauna der Miesmuschelbänke (Mytilus edulis L.) im Sylter Wattenmeer. Diploma thesis, University of Bonn, Germany

Hild A, Günther CP (1999) Ecosystem engineers: Mytilus edulis and Lanice conchilega. In: Dittmann S (ed) The Wadden Sea ecosystem: stability properties and mechanisms. Springer, Berlin Heidelberg NewYork, pp 43-49

Jacobi CM (1987) Spatial and temporal distribution of Amphipoda associated with mussel beds from the Bay of Santos (Brazil). Mar Ecol Prog Ser 35:51-58

Jones CG, Lawton JH, Shachak M (1994) Organisms as ecosystem engineers. Oikos 69:373-386

Kröncke I (1996) Impact of biodeposition on macrofaunal communities in intertidal sand flats. In: Dworschak PC, Stachowitsch M, Ott JA (eds) Influences of organisms on their environment: the role of episodic events. Proceedings of the 29th European marine biology symposium 1994, Vienna. (Pubblicazioni della Stazione Zoologica di Napoli: Marine Ecology 17) Blackwell, Vienna, pp 159-174

Lintas C, Seed R (1994) Spatial variation in the fauna associated with Mytilus edulis on a wave-exposed rocky shore. J Mollusc Stud 60:165-174

Mayer LM, Schick LL, Self RFL, Jumars PA, Findlay RH, Chen Z, Sampson S (1997) Digestive environments of benthic macroinvertebrate guts: enzymes, surfactants and dissolved organic matter. J Mar Res 55:785-812

McDermott JJ, Roe P (1985) Food, feeding behavior and feeding ecology of nemerteans. Am Zool 25:113-125 
McGrorty S, Goss-Custard JD (1991) Population dynamics of the mussel Mytilus edulis: spatial variations in age-class densities of an intertidal estuarine population along environmental gradient. Mar Ecol Prog Ser 73:191-202

Navarrete SA, Castilla JC (1990) Resource partitioning between intertidal predatory crabs: interference and refuge utilization. J Exp Mar Biol Ecol 143:101-129

Nehls G, Thiel M (1993) Large-scale distribution patterns of the mussel Mytilus edulis in the Wadden Sea of SchleswigHolstein: do storms structure the ecosystem? Neth J Sea Res 31:181-187

Nehls G, Hertzler I, Scheiffarth G (1997) Stable mussel Mytilus edulis beds in the Wadden Sea - they're just for the birds. Helgol Meeresunters 51:361-372

Nelson WG, Demetriades L (1992) Peracarids associated with sabellariid worm rock (Phragmatopoma lapidosa Kinberg) at Sebastian Inlet, Florida, USA. J Crustac Biol 12:647-654

Norkko A, Bonsdorff E (1996) Population responses of coastal zoobenthos to accumulations of drifting algal mats. Mar Ecol Prog Ser 131:143-157

Okun N (1999) Einfluss der Sedimentation auf die Miesmuschel (Mytilus edulis L.) Diploma thesis, University of Hamburg, Germany

Ong Che RG, Morton B (1992) Structure and seasonal variations in abundance of the macro-invertebrate community associated with Septifer virgatus (Bivalvia: Mytilidae) at Cape d'Aguilar, Hong Kong. Asian Mar Biol 9:217-233

Peake AJ, Quinn GP (1993) Temporal variation in species-area curves for invertebrates in clumps of an intertidal mussel. Ecography 16:269-277

Quijón P, Jaramillo E, Pino M (1996) Macrofaunal assemblages associated with mussel and clam beds in an estuary of Southern Chile. Estuaries 19:62-74

Ragnarsson SÁ, Raffaelli D (1999) Effects of the mussel Mytilus edulis L. on the invertebrate fauna of sediments. J Exp Mar Biol Ecol 241:31-43

Reise K, Herre E, Sturm M (1994) Biomass and abundance of macrofauna in intertidal sediments of Königshafen in the northern Wadden Sea. Helgol Meeresunters 48:201-215

Seed R (1996) Patterns of biodiversity in the macro-invertebrate fauna associated with mussel patches on rocky shores. J Mar Biol Assoc UK 76:203-210

Seed R, Suchanek TH (1992) Population and community ecology of Mytilus. In: Gosling EM (ed) The mussel Mytilus: ecology, physiology, genetics and culture. (Developments in aquaculture and fisheries science 25) Elsevier, Amsterdam, pp 87-169

Snover ML, Commito JA (1998) The fractal geometry of Mytilus edulis L. spatial distribution in a soft-bottom system. J Exp Mar Biol Ecol 223:53-64
Suchanek TH (1986) Mussels and their rôle in structuring rocky shore communities. In: Moore PG, Seed R (eds) The ecology of rocky coasts. Columbia University Press, New York, pp 7096

Svane I, Setyobudiandi I (1996) Diversity of associated fauna in beds of the blue mussel Mytilus edulis L.: effects of location, patch size, and position within the patch. Ophelia 45:39-54

Thiel M, Kruse I (2001) Status of the Nemertea as predators in marine ecosystems. Hydrobiologia 456:21-32

Thiel M, Vásquez JA (2000) Are kelp holdfasts islands on the ocean floor? - Indication for temporarily closed aggregations of peracarid crustaceans. Hydrobiologia 440:45-54

Thiel M, Watling L (1998) Effects of green algal mats on infaunal colonization of a New England mud flat - long-lasting effects, but highly localized. Hydrobiologia 375/376:177-189

Tokeshi M (1995) Polychaete abundance and dispersion patterns in mussel beds: a non-trivial infaunal assemblage on a Pacific South American rocky shore. Mar Ecol Prog Ser 125:137147

Tokeshi M, Romero L (1995) Filling a gap: dynamics of space occupancy on a mussel-dominated subtropical rocky shore. Mar Ecol Prog Ser 119:167-176

Topaloglu B, Kihara K (1993) Community of Mediterranean mussel Mytilus galloprovincialis Lamarck, 1819 in the Bosphorus strait. J Tokyo Univ Fish 80:113-120

Tsuchiya M, Bellan-Santini D (1989) Vertical distribution of shallow rocky shore organisms and community structure of mussel beds (Mytilus galloprovincialis) along the coast of Marseille, France. Mésogée 49:91-110

Tsuchiya M, Nishihira M (1985) Islands of Mytilus edulis as a habitat for small intertidal animals: effect of island size on community structure. Mar Ecol Prog Ser 25:71-81

Tsuchiya M, Nishihira M (1986) Islands of Mytilus edulis as a habitat for small intertidal animals: effect of Mytilus age structure on the species composition of the associated fauna and community organization. Mar Ecol Prog Ser 31:171178

Tsuchiya M, Retière C (1992) Zonation of intertidal organisms and community structure of small animals associated with patches of the mussel Mytilus edulis L. along the rocky coast of Dinard, Brittany, France. Bull Coll Sci Univ Ryukyus 54:47-81

Villbrandt M, Hild A, Dittmann S (1999) Biogeochemical processes in tidal flat sediments and mutual interactions with macrobenthos. In: Dittmann S (ed) The Wadden Sea ecosystem: stability properties and mechanisms. Springer, Berlin Heidelberg NewYork, pp 95-132

Zar JH (1984) Biostatistical analysis. Prentice-Hall, Englewood Cliffs, N.J. 